\title{
MAN, ENGINEERING AND ETHICS
}

In today's technologically advanced and science-driven societies, a tension arises between the natural process of using our rationality that focuses more or less on the purpose and the practical questions of using new pieces of knowledge that we have gained mostly through modern engineering and technologies. There is often a significant contradiction between that which the required changes should bring about and that which they bring about in reality. The fact here is that the social reality since we are present in it not only with our rationality but also with our desires and ideas often changes the acquired pieces of knowledge and their utilization in such a way that their impact in social reality can be and even become undesirable. The thoughts of some representatives such as e.g. the culture critic Hans Jonas or the social thinker G. Lipovetsky can serve as a starting point, whereby already some authors in the past, such as Erich Fromm in his work "To Have or to Be", point out this reality and offer a viable alternative that ultimately proves to be more satisfying to human individuals and societies.

Keywords: engineering, ethics, Technotronic, environment, man

\section{Man as a social being}

Today we often come back to problems of seeking in which there are contradictions between the required reality and the real reality in which the modern man finds himself. It seems that in his effort to change himself and the world man can very efficiently use not only the current sum of knowledge but thanks to modern technologies also materials that we gain from nature and that we change into various artificial materials and substances by means of technological processes. Here a tension arises between the natural process of using our rationality that focuses more or less on the purpose and the practical questions of using new pieces of knowledge that we have gained mostly through modern engineering and technologies. There is often a significant contradiction between that which the required changes should bring about and that which they bring about in reality. The fact here is that the social reality since we are present in it not only with our rationality but also with our desires and ideas often changes the acquired pieces of knowledge and their utilization in such a way that their impact in social reality can be and even become undesirable. The thoughts of some representatives such as e.g. the culture critic Hans Jonas [1] or the social thinker G. Lipovetsky [2] can serve as a starting point, whereby already some authors in the past, such as Erich Fromm in his work "To Have or to $\mathrm{Be}$ " [3], point out this reality. I argue that the alternatives that these thinkers bring will ultimately prove to be more satisfying to human individuals and societies.
Inspired by the opinions of these thinkers we have been intrigued by the cultural and social phenomenon of the city. The origin and development of urbanization that are related to this phenomenon can be seen already by the origins of civilization (India, Mesopotamia, etc.). The city as an artificial cultural formation of man creates the preconditions for the phenomenon of the concentration of relationships of man to man and of man to nature. In terms of economic and business activities this concentration brings along significant effects; however, it is also accompanied by its unwanted social sideeffects, namely especially limited or anonymous human relations that can manifest themselves and are manifested in a certain indifference to the outer world and even to other people [4]. Life in an urbanization center such as a city results in the life of man and people to be flooded with various elements that serve, in their nature, as a presentation of a seeming superiority of the power of man over the environment, but it is accompanied also by negative consequences that affect the identity of man and affect even his intimate space. At present, this is visible in the phenomena of modern civilization such as the megalopolis. Those of us living in densely populated cultured countries or directly in big cities do not even realize anymore how little of the hearty, warm affection towards other people we have left [5]. People are hospitable and friendly when their capacity for social contacts is not continuously overloaded [6]. We become aware of this when we come into a sparsely populated country where neighbors are separated by a greater distance, bad roads, and when we visit them in their homes and even though we have not been invited, we are

\footnotetext{
* Cyril Diatka

Department of General and Applied Ethics, Faculty of Arts, Constantine the Philosopher University in Nitra, Slovakia

E-mail: cyril.diatka@gmail.com
} 
welcomed very warmly. The accumulation of human masses in modern cities is partially to blame for the fact that due to the concentration of the human population that keeps changing, overlapping internally, we cannot see the human face directly anymore [7]. Our love to the neighbor vanishes without a trace in the mass of neighbors who are too close to each other. The greater the overpopulation, the greater the necessity for the individual to avoid any emotional participation, and thus in the cities there are theft, lies, murder, and rape in lively streets during daylight without the passers-by to intervene. The crowding of many people in a tight space results in a state of internal exhaustion, interpersonal relations disappear, which leads to expressions of dehumanization and this state often causes aggressive behavior [8].

\section{The purpose of engineering}

The importance and role of engineering in the life of man are clearly noticeable everywhere. Engineering is a phenomenon in which the specific ability of man to substitute his inadequate powers through the practical utilization of both natural materials and knowledge gained while working with this kind of materials is manifested in ambivalent ways. Ever since the more remote phases of civilization, engineering is characterized by the ability to surpass the given conditions in which man lives and to create a tool with which man changes the world, but thus he inevitably changes himself as well [9]. Even though some of his works did not express a great understanding for engineering, after a certain phase of his thinking the Scottish thinker Thomas Carlyle arrived at the opinion that inventors and designers should be honored as significant poets, artists, and philosophers [10, p. 50f.]. A different opposite opinion is held by the well-known cultural historian Jacob Burkhardt. According to him discoverers and inventors are not great because they do not express the internal content of time and the world and they do not deal with the world as a whole. In addition, they are replaceable since others would have come to the same results later on anyway. An artist, poet, and philosopher are irreplaceable because their individuality is unique [11].

\section{Attack on the environment}

When civilized humanity is destroying the living nature that surrounds and nourishes it in blind vandalism, it endangers itself by ecologic destruction. Man usually starts to become aware of his mistakes only when he experiences them in economic terms which, however, can already be too late. Man who has become used to changing his environment rather than himself but if humanity wants to survive in sustainable conditions, it has to change its narrow purpose-driven view of the world now (G. Bateson) [12]. Along with the generally known environmental pollution with litter, agents for the protection of plants, indirect, but also clear consequences of applied science and technical interference in both the natural and social environment emerge in the water, but also in the soil and air. On this level, not only legal but also significant ethical and value conflicts arise [13]. Looking at it from the viewpoint of purposefulness, various chemical substances, as well as other industrial products, should serve for the common good of people and not for the destruction of the environment [14]. These facts are ambivalent. After the strict restriction of DTT substances, the number of malaria cases has increased again. The parasites causing it have gradually become resistant. We are thus waking up from a soothing dream of inevitable progress of human culture and well-being even it should be at the expense of the natural environment - a dream that humanity had been dreaming until the mid- $20^{\text {th }}$ century. "In the second half of this century, the technological optimism gradually faded and was replaced by skepticism and negativism." [15, p. 35]

It is clear that the present man cannot abandon the journey on which he has set out already at the time of the birth of civilization. This applies to the European civilization as well where in addition to various changes in the area of spiritual life and a certain level of perceiving experience with one's own inner being. [16] With time, however, objectness appears in parallel in the acts of man and gains a certain upper hand over time. Objectness can also be understood as a process of objectification of human relationships where, in the effort to multiply the effects of this objectified action, there is always a certain tension, distrust, and rivalry in the human relationships. Sociology studies these issues from the viewpoint of inequality among people [17, pp. 25-30]. However, in our opinion, this problem is much more complicated. It seems that those who are suppressed and disadvantaged in the relationships of inequalities often react to their situation in ways that are not rational, but clearly irrational. Objectness in human relationships is graduated more or less based on the benefit that should be brought about by this very change often accompanied by the development of engineering and technologies [18]. However, everything man longs for and what the objectified realm offers him cannot be encompassed by the overall process of man's life into which we have to also include the incentives and motives of acts connected with man's ideas. Modern axiology that studies the processes that result from the tension between the real and fake values speaks of some the facts of this type. Here values are perceived in a certain sense as the basis and the goals of human activities. In these terms, it is important to analyze the concept of a value and value orientations. It appears that man as the recipient, creator, and source of values presents his value orientations and attitudes outwards through implemented decisions for which he is responsible. Thanks to modern axiology in this area we can perceive the process as if the value dimension of our life were disappearing whereby it is substituted by facts about reality and those seem to be the proof for instrumental thinking that that which is happening at the moment or that which we are enjoying thanks to our activities is 
not only necessary and useful, but also right. The individual life of man and the frequent occurrence of various degrees of mental illnesses in modern civilization prove that the problem is much more complicated. Man has to exert a certain considerably great effort not only while using new technical means and technological processes, but often he finds himself in a situation when he inevitably has to overcome the consequences of these technical and technological tools [19, pp. 36-37]. This is proved every day by modern medicine and its new dynamic field psychiatry. In other words, man can often manage engineering and technologies in the practical sense, but he cannot always manage himself. The pressure of the economic system that depends on the level of engineering and technologies is so intensive at present that rest and relaxation become a problem for the modern man. The mass of individuals has to adapt to this system under a certain program, whereby the individual life becomes only its accessory.

Another, critical view of engineering and the use of engineering is provided by authors affiliated with the personalistic concepts of man. As Valco and Sturak argue in their recent study, "[c]ountering the forces of depersonalization and dehumanization which ran rampant in the course of the 20th century, the personalist movement (Mounier, Maritain, etc.) has made a solid attempt to lay the foundations for protecting human dignity, reorienting modern philosophical endeavors to focus again on basic questions of anthropology." [20, p. 289] The so-called "technical man" does not do justice to a competent, holistic understanding of man's nature on the level of philosophical anthropology. According Edward Spranger, the technical man is not a special type in terms of uniqueness at all, but it is a mixed type connecting science and economy. A typical characteristic of engineering is that in itself it does not create a separate type of values. "A technician, as long as he is only a real technician, is not interested in value or the value of the goal for which he is seeking means based on the laws of events and economic forces in the direct sense of the word. He assumes that this decision about the value has been made on different grounds than engineering, simply in a different part of the soul" [21, p. 362]. As far as individuals are concerned who strongly prefer the conveniences of engineering in their lives and also subordinate their lifestyle to them, the Czech sociologist E. Urbanek says that their individual rationality inevitably changes into technical rationality. Further, technical rationality inevitably changes into the rationality of subordination which is always closely connected with the development of bureaucracy [17, p. 11]. Thus a clear tendency to technocratism arises that views the life of the modern man more or less instrumentally as a certain thing or part of a system. On such a level of perception, everything is replaceable and interchangeable in a relatively short period of time. Marcuse emphasizes this fact in his work OneDimensional Man (1964) [22]. Lewis Mumford, a US-American sociologist, also arrives at a similar conclusion as H. Marcuse. In his book, The Myth of the Machine (1971), Munford describes the type of a so-called organized man [23]. He comes with the idea that the more perfect the mechanism is going to be, the smaller and less important is the rest of life, which however is necessary for technical life to go on.

We come back to the phenomenon of the city, i.e., the space that arises as a new reality of its kind of relationships of man to man and the environment. Thanks to the city and the development of city urbanization there is an ever-growing imbalance of the stated relationships, new structures of evil, the ability to use nature or the environment indirectly in a limited framework of technical rationality have been formed. The industrialization period that preceded the current civilization development has brought these facts to the surface in the form of objectified relationships based on technical rationality that reduces naturally personally created communities in such a sense that even a specific human relationship gains an evidently estranged form. This is accompanied by various forms of the loss of the sense of belonging accompanied by the state of internal exhaustion all the way to the boundary of endangering the personal identity. Here we can find the explanation why totalitarian regimes based on the manipulation of masses sprung up in the first half of the $20^{\text {th }}$ century. Problems of indifference to the outer world, but also to other people have occurred. At present when communication technologies dominate, due to advertisements and the influence of people (television) the life of people is flooded with various patterns of behavior that stress quick change and an evident subordination of man to the predominant technical wave [4, p. 330]. From some TV programs, stories keep disappearing in which man is depicted as someone fighting for a certain value experienced in the given situation at the expense of the outer effect that is highlighted with irony changing even to a comical situation. A very clear example of this are the so-called sitcoms that are shown on TV so often. This results in a situation when it can be said that the present people can be entertained, but they cannot rejoice heartily. This kind of entertainment brings quick and short satisfaction which is followed by quick sobering that makes itself felt in a certain inner tension that accompanies man during his everyday life. This is similar to the quick consumption of a delicious meal where at the state of fullness the result is a certain surfeit instead of satisfying hunger. A new, up to a certain point unknown culture arises that has massively spread and that can be called postmodern [24] in the sense that it places into the foreground a testimony and service to facts and not ideals [25, p. 63]. This is an evident favoring of facts over values.

Our relationship to nature and the environment evolves in a similar way. With growing urbanization and the establishment of the modern megalopolis, we are confronted with frequent cases of atmosphere, air, water, and soil pollution. This fact leads us to the knowledge that under the given circumstances we are not always able to limit some effects of industrially produced substances. A very grave problem also arises with respect to the human body, e.g. how to solve the side effects of drugs, what to do with radioactive waste, etc. How to solve the multiple exceeding of 


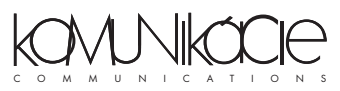

norms of air pollutant emissions? While considering the question of how far humanity is able to go, the problem of legal and ethical responsibility arises, especially as far as the improvement of nourishment and the quality of human life are concerned. We are not always able to detect the immediate cause of an unwanted state; often only the synergic effects are harmful that arise through the combination of sublimely culminating effects. It is these effects that lead to the exceeding of the toxic threshold limit value. Harmfulness caused by a synergic effect very often makes it impossible to find specific causes of the given state. The accumulation of causes and their relative uncontrollability usually top off the damage caused. The unwanted becomes reality [26].

If we understand the current ecologic crisis in the context of both social relationships and the overall globalizing activities of the present humanity, it is impossible not to see the fact that these relationships have the tendency to accumulate in local, i.e. specific geographic areas [27]. At the same time we need to become aware of the fact that economic evaluation of all activities is predominating due to which short-term strategies focusing on increasing the profit are most common and thus there is a growing discrepancy between these short-term strategies and the longterm perspectives of development including the protection of life and the preservation of life forms on this planet (the problem of biodiversity). "All ecological projects are not socially neutral, just like social and political projects are not ecologically neutral. Human social activities form the environment and no society can avoid unintended economic consequences" [7, p. 185].

\section{The responsibility of science and engineering}

One of the significant representatives of postmodernism J. F. Lyotard (1924-1998) [28] points out a completely new situation in the current science and especially in the use of language. According to Lyotard various technologies that use scientific knowledge and thus are presented by a specific language that changes into a discourse, change the language into an artificial language. Lyotard mentions technologies like phonology, various levels of linguistics including cybernetics, modern algebra, and informatics. A new type of language enters the reality of human communication, and it is further adapted so that it is compatible with computer language. This concerns the issues of facts and the use of facts, their storing in memory, and the creation of various databases, whereby the entry of these technologies into this reality of language changing has not been completely exhausted yet [28, p. 100]. Knowledge in such science disciplines of postmodern society as are informatics and cybernetics assumes a uniform language of a digital code that eliminates every ambiguity or polysemy. This new situation affects the character of knowing itself. Pieces of knowledge can go through new channels and become usable only if they can be expressed in an information language. Based on this we can assume that that which cannot be interpreted into an information language will be gradually excluded from the traditional understanding of knowing [29]. We will subordinate the new research, its findings to the condition of it being translatable into a computer language. The relation to one single code means that knowing as a sum of pieces of knowledge becomes superficial and transferable in contrast to "knowledge" regardless of the fact on which level of the cognitive process it is found. The old principle according to which the spreading of knowledge by individuals was connected to the formation of their spirit and the personality of the researcher itself is in a decline. The knowing of today is subject to the law of supply and demand. Pieces of knowledge are produced to be sold; they are continuously consumed and appreciated in a new production. Knowing is not a purpose in itself, it is losing its utility value.

At present, knowing is actually becoming a productive force that is at the same time a strategic weapon in the world competition for power. In our opinion, today the battle is about conquering information in such a way as there were battles for territories and sources of raw materials in the past. We are witnesses of the fight for cheap labor the consequences of which are new economic, military, and political strategies. In the field of science and engineering, ethical problems come to the fore more and more intensively. This is a result of the process of the continuously growing disposition power of man over both the environment and himself. In relation to this we can encounter new possibilities of manipulation [30].

\section{The threat of technotrony}

At present, the technology of data processing presents a significant breakthrough. Microelectronics, computer-controlled system and automated organization of administration based on electronic data processing are developing intensively. In relation to this there is a tendency of growing technocracy which efficiently brings together bureaucracy, technocracy, and electronocracy. This connection represents the well-known biblical "mene mene tekel ..." [31] more and more. Let us just imagine a great amount of data written on magnetic media of industrially developed societies. An almost exponential development of computer engineering and along with it electronic processing of data and information. The problem of protecting the privacy of individuals is more and more pressing. The collection and combination of personal data currently provides room for complete control of persons. The threat to privacy, the need to keep personal data confidential have opened a serious legal problem of data protection, especially of protecting personal data from commercial and overall social misuse [32].

This problem brings along a significant moral burden that affects every member of the society. The new task of knowing in morality (H. Jonas [1]) is related to this problem as well as to others that have been mentioned by us. In this ever-changing 
situation knowing becomes our urgent obligation. We have to deal with a whole breadth of our causal dimension of action. This fact points out that this is not always possible and this leads us to the conclusion that foresighted knowing lags behind technical knowing. The chasm between the power of foresighted knowing and our ability to act in a quickly changing reality due to modern engineering and technology creates a new ethical problem. The acknowledgment of our unfinished knowing is the opposite of our obligation to develop this knowledge. This fact if we understand it correctly should lead us to greater caution in regard to our continuously growing power. "None of the previous ethics had to consider the global conditions of human life or distant future and thus the existence of the humankind as a whole," writes Hans Jonas [1, p. 29] in his book The Imperative of Responsibility (Czech translation, 1997). It is clear that we have to consider more than just our pure human interest. With his activities in the area of engineering and technologies man came into a position that our responsibility towards the social and natural environment is broader than before. The anthropocentric dimension is not sufficient anymore. It makes sense to ask, quite responsibly " [...] whether the status outside of human nature, the biosphere as a whole and its parts that are subordinate mostly to our power did not become an entrusted good for us, people, and thus the moral claim towards us changes - not only thanks to us, but also for himself and out of his own right” [1, p. 29]. Hans Jonas points out that the more our power grows when interfering with the outer world, our position inevitably changes and it requires a new attitude as well. This is an acknowledgement of "purposes about oneself" also outside of the human area, "... and to see to it that these facts are included into the concept of human good" [1, p. 29]. Also thanks to these thoughts the tradition of the current scientific knowledge gives us the opportunity to think about nature more or less in a reduced form. As if only from the position of necessity and chance. This problem can also be viewed in such a way that from the wealth of the natural world endangered by us an unspoken appeal arises to protect its integrity. Is nature worth moral attention from our side? [26]

\section{Conclusion}

We would be foolish to hope to disentangle this complex array of issues in one short article. Our ambition rather is to show how a competent and focused analysis of the mentioned problems points us to several critical considerations: (1) we should be less optimistic about the ability and readiness of man to somehow "naturally" use the latest advances in science and technology to create a "better" and more "just" world; (2) facing the fact that we are oftentimes mistaken about the long-term impacts of our applied scientific research and the employment of new technologies, intellectuals, scientists and the academic community as a whole should assume a more humble attitude when they talk about the future promises of new scientific discoveries (both, in terms of epistemic and communicative humility); (3) we must be critically aware of the interconnections among economy, science, ecology, and social realities. Only a holistic, integrative approach stands a good chance of bringing satisfactory and sustainable results. Yet, this whole process of critical reflection should start with an anthropological re-evaluation of the human predicament. We had better seriously take into account man's corruption and come up with a realistic, rather than overly optimistic anthropology. We are speaking here of a "condition of disconnectedness and alienation on both, the horizontal and vertical levels.” [20, p. 291] There are limits of what we can achieve by mere cultivating of our reasoning skills and enhancing our knowledge of the natural world. "We are able, in this condition, to develop and use our faculties of reason, emotion, and will, but our rationality in this 'alienated state' tends to be used to justify and attain the desires of a proud or despairing, but always hopelessly self-centered human heart. Rationality does not always develop into veracity (i.e., the desire of the moral subject to know and attain the truth) and the kind of freedom that we derive from our rational striving is divorced from the unity of Truth, Beauty and Goodness that we ultimately covet.” [20, p. 291] Therefore, the challenge of sustainable development and future interactions between man, nature, and technology cannot be answered without a competent and realistic anthropology anchored in a robust, holistic understanding of our global world in its multiple and yet interconnected dimensions. To be able to see this clearly, we need to cultivate the "ability to engage in the so-called 'second order discourse', that is, being able to analyze the metaphysical pre-suppositions" [33, p. 147] of all who are engaged in the pursuit of wisdom - whether individually (as part of an inner process of critical introspection) or communally.

\section{References}

[1] JONAS, H.: The Principle of Responsibility (in Czech). Oykumeneh, Praha, 1997.

[2] LIPOVETSKY, G.: Hypermodern Age (in Czech). Prostor, Praha, 2013.

[3] FROMM, E.: To Have Or To Be? Bloomsbury, London, 2013.

[4] LESKOVA, A., VALCO, M.: Identity of Adolescents and Its Dimensions in the Relation to Mass Media: Philosophical and Ethical Reflections. XLinguae, 10(3), 324-332, 2017. Recent studies focused particularly on the influence of audiovisual mass media on 
the adolescents (or the so-called "emerging adults"), showing their growing detrimental impact in terms of desocialization and individualization. See: Ibid., p. 329-330.

[5] BAUMAN, Z.: Liquid Modernity (in Czech). MF, Praha, 2002.

[6] SOKOL, J.: Time and Rhythm (in Czech). Praha, 2. Edition. Oykumeneh, 2004. See also: HUBA, M., NOVACEK, P. (Ed.): The Shock of Prosperity: A Reader in Global Issues (in Slovak). Spol. pre trval. udr. zivot, Bratislava, 1995.

[7] HARVEY, D.: Justice, Nature and the Geography of Difference. Blackwell, Oxford, 1996.

[8] BUCHANAN, J.P.: The Death of the West (in Czech). Cytadela, Brno, 2012; TONDL, L.: Science, Technology, and Society (in Czech). Filozofia, Praha, p. 184, 1994; TURCAN, C.: Hans Jonas' Ethics of Technology: Risks of Technological Society. Communications - Scientific Letters of the University of Zilina, 19(1), 35-38.

[9] GEHLEN, A.: Spirit in the World of Technology (in Czech). Svoboda, Praha, 1972.

[10] CARLYLE T.: Critical and Miscellaneous Essays. A. Hart, Philadelphia, 1852.

[11] SAX, B. C.: State and Culture in the Thought of Jacob Burckhardt. Annals of Scholarship, 3(4), 1-35, 1985,

[12] BATESON G.: Mind and Nature: A Necessary Unity. Dutton, New York, 1979.

[13] BUNGE, M.: Technology as Applied Science. F. Rapp, Contributions to a Philosophy of Technology. D. Reidel Publ. Comp., Dordrecht, Boston, 1974.

[14] PECKA, D.: Man and Technology (in Czech). Vysehrad, Praha, 1969.

[15] TURCAN, C.: Hans Jonas' Ethics of Technology: Risks of Technological Society. Communications - Scientific Letters of the University of Zilina, 19(1), 35-38, 2017.

[16] Existentialist thinkers pointed out this lack of depth already in the $19^{\text {th }}$ century. Among them, S. Kierkegaard, the Danish religious existentialist, "analyzed the problems of society and of the private individual (values, loss of subjectivity, the impact of journalism, and the decline of the church)" and who helped the future generations of intellectuals to refocus again on the role of subjectivity, and the individual and inner dimensions of man" (p. 323). PAVLIKOVA, M.: Kierkegaard's Understanding of Man and Society. XLinguae, 11(1), 323-331, 2018. On this topic see also: TAVILLA, I., KRALIK, R., MARTIN, J. G.: A brief Recollection of Kierkegaard's Testimony on Reformation 500th Anniversary. XLinguae, 11(1), 353-362, 2018; and MAHRIK, T.: Truth as the Key Metaethical Category in Kierkegaard. XLinguae, 11(1), 40-48, 2018.

[17] URBANEK, E., BURIANEK, J.: Basics in Sociology (in Czech). S\&M, Praha, 1991.

[18] TONDL, L.: Science, Technology, and Society (in Czech). Filozofia, Praha, p. 184, 1994.

[19] TURCAN, C.: Hans Jonas' Ethics of Technology: Risks of Technological Society. Communications - Scientific Letters of the University of Zilina, 19(1), 35-38, 2017.

[20] VALCO, M., STURAK, P.: The "Relational Self”: Philosophical-Religious Reflections in Anthropology and Personalism. XLinguae, 11(1), 289-299, 2018.

[21] SPRANGER E. Types of Men. PIGORS, P. (Tran.). Niermeyer, Halle, Germany, 1928.

[22] MARCUSE, H.: A Unidimensional Man (in Czech). Nase vojsko, Praha, 1991.

[23] MUMFORD L.: Technics and Human Development: The Myth of the Machine, vol. I. Harvest Books, Chicago, 1971.

[24] GUARDINI, R.: End of Modernity (in Czech). Vysehrad, Praha, 1992.

[25] LIPOVETSKY, G.: The Twilight of Responsibility. A Painless Ethics in New Democratic Times (in Czech). Prostor, Praha, 1999.

[26] SKYBOVA, M.: Ethics and Nature. Why should we care morally about Nature? (in Czech). Vydavatelstvo Mervart, Praha, p. 196, 2011.

[27] HYKISCH, A.: Let us not Fear the World. A Guide to Global Thinking (in Slovak). Lizard, Bratislava, p. $371,2001$.

[28] LYOTARD, J. F.: On Postmodernism. Postmodernism Explained to Children. The Postmodern Situation (in Czech). Filosoficky ustav AV CR, Praha, 1993.

[29] SUSA, O.: Towards an Interpretation of Modernization under the Conditions of Current Crises of Natural Environment (in Czech). Acta Universitates Caroline, Karolinum, Praha, 37-59, 1996.

[30] STAHEL, R., SUSA, O.: Environmental Devastation and Social Destruction (in Czech). Filozofia Praha, p. $258,2016$.

[31] A reference to the Old Testament Book of Daniel, Chapter 5, verse 25. The words mean that God had "numbered" the days of the kingdom of Belshazzar and brought it to an end; the king had been weighed and found guilty; and that his kingdom was divided and given to the Medes and Persians.

[32] For a comparative study of US and EU approaches see: STEINKE G.: Data Privacy Approaches from US and EU Perspectives. Telematics and Informatics, 19(2), 193-200, 2002.

[33] VALCO, M.: Chemnitz's Eucharistic Christology as an Impulse for Ecumenical Dialogue between East and West. Konstantinove listy, 19(2), 141-150, 2017. 